\title{
BODY MASS INDEX, WEIGHT GAIN DURING PREGNANCY AND OBSTETRIC OUTCOMES
}

\author{
V. N. ADDO \\ Department of Obstetrics and Gynaecology, Komfo Anokye Teaching Hospital and School of Medical \\ Sciences, College Of Health Sciences, Kwame Nkrumah University of Science and Technology, Private Mail \\ Bag, Kumasi, Ghana
}

Corresponding Author: Dr. V.N. Addo

Conflict of Interest: None declared

\section{SUMMARY}

Objectives: To find out the effects of pregnancy weight gain in different body mass index (BMI) groups on maternal and neonatal outcomes in women delivering singletons at term.

Design: Retrospective analysis of clinical records of patients attending antenatal clinics and delivering in hospital from January 1st 1992 to December 31st 2009. Setting: A private specialist hospital.

Methods: The records of patients starting antenatal care in the first trimester, attending at least four clinics and delivering singletons from 37 completed weeks up to 42 weeks gestation were analysed. Patients' booking gestational age, height, weight and obstetric and neonatal outcomes at delivery were noted.

Results: The total number of deliveries was 2,391 out of which 1755 (72.4\%) were analysed. The overweight and obese group compared to the normal were significantly older, shorter, weighed more at booking and gained more weight during pregnancy. The overweight or obese were significantly more likely to have induction of labour and be delivered by caesarean section compared to the normal. Maternal and neonatal outcomes which were more significant in the overweight and obese were macrosomia, stillbirth, perineal trauma, post-partum haemorrhage and retained placenta.

Conclusions: Most deliveries in the two BMI groups resulted in normal weight babies. Overweight and Obesity is associated with significantly increased incidence of adverse maternal and neonatal outcomes. It is recommended that further studies involving larger samples comparable to those done in western countries are carried out.

Keywords: body mass index, gestational weight gain, obstetric outcomes, neonatal outcomes, Ghana

\section{INTRODUCTION}

Maternal weight gain in pregnancy can offer a good means of assessing the wellbeing of the pregnant mother and, by inference of her baby. ${ }^{1}$ Inadequate
Email:vn_addo@yahoo.com

prenatal weight gain is a significant risk factor for intra-uterine growth restriction, pre-term delivery and low birth weight in infants. ${ }^{2,3,4,5}$ Obesity and excessive weight gain on the other hand can lead to adverse maternal and foetal outcomes. ${ }^{6,7}$ These have led to suggestions for optimal weight gain to ensure the best outcomes. $^{8,9,10}$ The Institute of Medicine (IOM) published recommended weight gains by prepregnancy BMI which have been the standard for subsequent research. ${ }^{11}$ These recommendations are for BMI $<19.8 \mathrm{~kg} / \mathrm{m}^{2}$ total weight gain between 12.5 to 18 $\mathrm{kg}$; $\mathrm{BMI}=19.8$ to $26.0 \mathrm{~kg} / \mathrm{m}^{2}$ total weight gain between 11.5 to $16 \mathrm{~kg}$; $\mathrm{BMI}>26.0$ to $29.0 \mathrm{~kg} / \mathrm{m}^{2}$ total weight gain between 7.0 to $11.5 \mathrm{~kg}$. and for BMI $>29.0 \mathrm{~kg} / \mathrm{m}^{2}$ total weight gain of $7.0 \mathrm{~kg}$.

In earlier research the relationships between maternal height and weight with pregnancy complications were extensively explored, but in recent times, BMI is widely accepted as a better measure of over or underweight. $^{12}$ More recently, the waist-hip ratio has been used to study the effects of obesity on pregnancy, but data relating to this parameter are seldom available. ${ }^{13}$ The studies conducted so far are from Western developed countries and there is a paucity of data from developing countries. ${ }^{14}$ This study was done to find out the effects of pregnancy weight gain in different BMI groups on maternal and neonatal outcomes in women delivering singleton babies at term.

\section{PATIENTS AND METHODS}

The records of all patients who started their antenatal care in the first trimester, attended for antenatal care on at least four occasions and delivered in the hospital between 1st January, 1992 and 31st December, 2009 were retrieved. Using a population parameter of $34 \%$ for overweight and obese pregnant women, a sample size of 1755 was estimated at $95 \%$ confidence interval with $5 \%$ error margin and $80 \%$ power. $^{14}$

This study was conducted in Bomso Specialist Hospital in Kumasi, Ghana. This private hospital is situated in a 
busy cosmopolitan area close to the Kwame Nkrumah University of Science and Technology campus. Patients come from various private enterprises including mining companies, financial institutions and non-governmental organizations as well as local residents.

The Hospital offers specialist services in Medicine, Surgery, Paediatrics and Obstetrics and Gynaecology. The current delivery averages 100 annually. Only women carrying singleton pregnancies who delivered between 37 and 42 completed weeks were included. Data collected included demographic details, height and the weight at booking and at every visit. Body mass index (BMI) was calculated using the formula:

\section{Weight in kilograms/ (height in metres) ${ }^{2}$}

Booking BMI was categorised as underweight (BMI $\leq$ $18.5)$, normal $(\mathrm{BMI}=18.6-25.0)$, overweight $(\mathrm{BMI}=$ 25.1-30.0), and obese (BMI $\geq 30.1) .{ }^{15}$ Gestational age (GA) was recorded according to the first day of the last normal menstrual period (LMP). Ultrasound scandating was performed at the first visit. If the two were in agreement, the LMP GA was used. The LMP and scan date were not to differ by more than ten days. If the difference was more than ten days then the booking scan GA was taken as the gestational age. The dating scans were performed between 10 and 13 weeks using the crown-rump length to determine gestational age. ${ }^{16}$

Gestational weight gain was defined as the difference between the maternal weight measured within one week prior to delivery and the maternal weight recorded at the first visit to the hospital. Gestational weight gains were grouped into three categories as low weight gain $(\leq 8.0 \mathrm{~kg})$, normal weight gain $(8.1-16.0$ $\mathrm{kg})$ and high weight gain $(\geq 16.1 \mathrm{~kg}) .{ }^{17}$ Labour and delivery outcomes analyzed were onset of labour (spontaneous or induced), and route of delivery-vaginal (spontaneous or vacuum extraction/forceps delivery) or caesarean section. Maternal postpartum outcomes were postpartum haemorrhage, retained placenta and perineal trauma. Neonatal outcomes were birthweights, admission to neonatal intensive care unit (NICU) and stillbirths. Infant birth weights were characterized as low birthweight $(\mathrm{LBW}) \leq 2.50 \mathrm{~kg}$, normal birthweight $(\mathrm{NBW})=2.51-3.99 \mathrm{~kg}$, and macrosomia $\geq 4.00 \mathrm{~kg}$. Data were coded and analyzed using SPSS, version 15 (SPSS, Chicago, IL, USA) and the Epidemiological Calculator, version 2.7.0 (EpiCALC).

Frequency and proportional distribution were made to assess the distribution of observations under the three categories - obesity, overweight and underweight). For the purposes of inferential statistics, the chi square test or Fisher's exact test was used for data categorised in nominal terms to determine whether there is an association or otherwise between the variables. Student $t$ test was used for numerical data for purposes of determining significant relationship or otherwise of observations about the three categories. The significance of an association was considered at pvalue less than 0.05 .

An Odds ratio (OR) was used to determine the effects of difference among the three groups using Normal BMI as reference. The $95 \%$ confidence interval (C.I.) of an OR estimate was also determined.

\section{RESULTS}

The total number of deliveries during the study period was 2,391 out of which 1755 (73.4\%) satisfied the study criteria. The BMI at booking classified $77 / 1755$ (4.4\%) women as underweight, 832/1755 (47.4\%) as normal weight, $609 / 1755(34.7 \%)$ as overweight and $314 / 1755(17.9 \%)$ as obese. Parity ranged from 0 to 6 (median $=2$ ). None of the patients smoked cigarettes nor drank alcohol and enjoyed good support from their spouses. The results of women with normal BMI are compared to those of women in the overweight and obese groups. The number of women in the underweight group was small (4.4\% of the total study population) and was excluded from analysis.

Table1 shows that women in the overweight and obese group were significantly older, shorter and had higher booking weight than those in the normal group. The mean weight gain between the two groups was not statistically significant $(\mathrm{p}=0.37$; [95\% C.I. -0.31 , $0.11])$.

Table 2 shows total weight gain by booking BMI. Total weight gain was normal in $1385 / 1755(78.8 \%)$ of the patients. There was a statistically significant total weight gain in the overweight and obese compared to the normal. $(p<0.01,95 \% \mathrm{CI}=[6.41(3.63,12.0])$.

Table 3 shows labour and delivery outcomes. Induction of labour and delivery by caesarean section were statistically more significant in the overweight and obese group.

Neonatal and maternal post-partum outcomes are shown in Table 4. In both BMI groups most of the newborns were of normal weight. Outcomes which were statistically significant in the overweight and obese were macrosomia, stillbirth, perineal trauma, post-partum haemorrhage and retained placenta. Outcomes which did not show significant associations were LBW babies and admission to NICU. 
Table 1 Characteristics of patients in the different BMI groups

\begin{tabular}{|c|c|c|c|c|c|}
\hline Characteristics & $\begin{array}{c}\text { Normal } \\
(B M I=18.6-25.0) \\
\text { Mean (SD) } \\
\end{array}$ & $\begin{array}{c}\text { Overweight }+ \text { Obese } \\
(\text { BMI } \geq 25.1) \\
\text { Mean }(\text { SD) } \\
\end{array}$ & t-test & p-value & $\begin{array}{l}95 \% \text { CI of Mean } \\
\text { difference }\end{array}$ \\
\hline Age at delivery(yrs.) & $28.1(5.1)$ & $30.2(4.8)$ & 8.88 & $<0.01$ & {$[1.63,2.56]$} \\
\hline Height (m.) & $1.62(0.07)$ & $1.59(10.1)$ & -8.96 & $<0.01$ & {$[-0.03,-0.02]$} \\
\hline Booking weight (kg.) & $57.4(7.9)$ & $77.2(9.98)$ & 45.74 & $<0.01$ & {$[18.95,20.64]$} \\
\hline Mean weight gain(Kg.) & $10.0(2.0)$ & $9.9(2.6)$ & -0.89 & 0.37 & {$[-0.31,0.11]$} \\
\hline $\begin{array}{l}\text { Number of subjects } \\
\text { (\% of total 1755) }\end{array}$ & $832(47.4 \%)$ & $923(52.6 \%)$ & & & \\
\hline
\end{tabular}

Table 2 Total weight gain by booking BMI

\begin{tabular}{|c|c|c|c|c|c|}
\hline Characteristics & $\begin{array}{c}\text { Normal } \\
(\mathrm{BMI}=\mathbf{1 8 . 6}-\mathbf{2 5 . 0}) \\
\mathrm{N}=\mathbf{8 3 2}(\mathbf{4 7 . 4 \% )}\end{array}$ & $\begin{array}{c}\text { Overweight + Obese } \\
\text { (BMI } \geq 25.1) \\
\mathrm{N}=923(52.6 \%)\end{array}$ & $\begin{array}{c}\text { Chi } \\
\text { square }\end{array}$ & p-value & $\begin{array}{c}\text { Odds Ratio, } \\
95 \% \text { CI of OR }\end{array}$ \\
\hline $\begin{array}{c}\text { Low weight gain } \\
\leq 8.0 \mathrm{Kg} . \\
N=259\end{array}$ & $124(14.9)$ & 135 (14.6) & 0.41 & 0.52 & $1.09[0.82,1.44]$ \\
\hline $\begin{array}{c}\text { Normal weight gain } \\
(8.1-16.0 \mathrm{Kg}) \\
\mathrm{N}=1385\end{array}$ & $693(83.3)$ & $692(75.0)$ & & & \\
\hline $\begin{array}{c}\text { High weight gain } \\
\geq 16.1 \mathrm{Kg}, \\
\mathrm{N}=111\end{array}$ & $15(1.8)$ & $96(9.4)$ & 54.99 & $<0.01$ & $6.41[3.65,12.0]$ \\
\hline
\end{tabular}

Table 3 Labour and delivery outcomes

\begin{tabular}{|c|c|c|c|c|c|}
\hline & $\begin{array}{c}\text { Normal } \\
(B M I=\mathbf{1 8 . 6}-25.0) \\
\text { N }=\mathbf{8 3 2}(\mathbf{4 7 . 4 \% )}\end{array}$ & $\begin{array}{c}\text { Overweight }+ \text { Obese } \\
(\text { BMI } \geq 25.1) \\
\mathrm{N}=923(52.6 \%)\end{array}$ & $\begin{array}{c}\text { Chi } \\
\text { square }\end{array}$ & p-value & $\begin{array}{l}\text { Odds Ratio, } 95 \% \\
\text { CI of OR }\end{array}$ \\
\hline \multicolumn{6}{|c|}{ Labour and delivery outcomes } \\
\hline \multicolumn{6}{|l|}{ Labour } \\
\hline Spontaneous & $799(96.0)$ & $859(93.1)$ & & & \\
\hline Induced & $33(4.0)$ & $64(6.9)$ & 7.38 & $<0.01$ & $1.80[1.15,2.87]$ \\
\hline $\begin{array}{l}\text { Delivery } \\
\text { "Spont.Vaginal }\end{array}$ & $738(88.7)$ & $695(75.3)$ & & & \\
\hline Caesarean section & $84(10.1)$ & $217(23.5)$ & 55.54 & $<0.01$ & $2.74[2.07,3.64]$ \\
\hline Vacuum/forceps & $10(1.2)$ & $11(1.2)$ & 0.12 & $<0.72$ & $1.16[0,45,3.08]$ \\
\hline
\end{tabular}

Spont $=$ spontaneous

"Reference: group 
Table 4 Neonatal and maternal postpartum outcomes

\begin{tabular}{|c|c|c|c|c|c|}
\hline Outcome & $\begin{array}{c}\text { Normal } \\
(\mathrm{BMI}=\mathbf{1 8 . 6}-\mathbf{2 5 . 0}) \\
\mathrm{N}=\mathbf{8 3 2}(\mathbf{4 7 . 4 \% )}) \\
\end{array}$ & $\begin{array}{c}\text { Overweight }+ \text { obese } \\
(\text { BMI } \geq 25.1) \\
\mathrm{N}=923(52.6 \%) \\
\end{array}$ & $\begin{array}{c}\text { Chi } \\
\text { square }\end{array}$ & p- value & $\begin{array}{l}\text { Odds Ratio, } \\
\text { 95\% CI of OR }\end{array}$ \\
\hline $\begin{array}{l}\mathrm{LBW} \leq 2.50 \mathrm{Kg} \\
\text { Normal BW }\end{array}$ & $44(5.3)$ & $36(3.9)$ & 0.47 & 0.49 & $0.85[0.53,1.37]$ \\
\hline $\begin{array}{l}(2.51-3.99 \mathrm{Kg} .) \\
\text { Macrosomia }\end{array}$ & $790(95.0)$ & $757(82.0)$ & & & \\
\hline$\geq 4.00 \mathrm{Kg}$ & $12(1.3)$ & $101(10.9)$ & 68.99 & $<0.01$ & $8.78[4.75,17.69]$ \\
\hline NICU* & $34(4.1)$ & $47(5.1)$ & 2.03 & 0.15 & $1.39[0.86,2.25]$ \\
\hline Stillbirth & $9(1.1)$ & $28(3.0)$ & 9.59 & $<0.01$ & $3.12[1.42,7.57]$ \\
\hline Perineal trauma & $16(1.9)$ & $32(3.4)$ & 5.23 & $<0.01$ & $2.00[1.05,3.95]$ \\
\hline Postpartum Haemorrhage & $25(3.0)$ & $45(4.9)$ & 5.53 & 0.02 & $1.81[1.07,3.11$ \\
\hline Retained placenta & $9(1.1)$ & $35(3.8)$ & 15.02 & $<0.01$ & $3.90[1.82,9.29]$ \\
\hline
\end{tabular}

\section{DISCUSSION}

Maternal weight is recorded at almost all antenatal attendances and weight gain is considered to be a significant clinical test in antenatal care. Maternal weight gain is also a measurement frequently discussed by the patient in consultation with her doctor or midwife. Concern is often expressed if the patient does not gain weight as the pregnancy progresses. The amount of maternal weight gain that is compatible with a normal outcome has been the matter of debate since the 1940s. ${ }^{18,19,20}$ These have led to studies resulting in recommended weight gains in pregnancy. ${ }^{21}$ While most reports define obesity as an increased body mass index of greater than or equal to $30 \mathrm{~kg} / \mathrm{m} 2$ (IOM), others have defined it as increased waist circumference, increased waist - hip ratio or body weight of more than $90 \mathrm{Kg}$. This makes comparison of studies difficult and may have implications in the management of normal pregnancy.

Obesity in Ghana is increasing especially among females. ${ }^{22,23}$ Maternal obesity has long been correlated with an increased risk of chronic hypertension and diabetes prior to pregnancy and adverse pregnancy outcomes including pre-eclampsia, gestational diabetes, fetal macrosomia and caesarean deliveries. $^{24,25}$ The perinatal problems that have been identified with maternal obesity and pregnancy include an increased risk of birth asphyxia, birth trauma, and neonatal hypoglycaemia. ${ }^{26}$ In this study, risk factors associated with overweight and obesity were increased induction of labour, caesarean sections, macrosomic babies, stillbirths, perineal trauma, post-partum haemorrhage and retained placenta.

The limitations of this study were the relatively small sample size and that it was conducted in a private clinic. The low ratio of underweight patients may be a reflection of the generally good nutritional status of these patients and also the general notion among Ghanaians that being plump is a reflection of wellbeing. It is likely that if the sample size were larger or if the study were done in a public hospital other significant obstetric and neonatal complications would have been found.

This study, though involving relatively small numbers, adds to the increasing body of evidence which suggests that obesity, measured by BMI, predisposes women to complicated pregnancies and increased obstetric interventions. Obstetrically, obese women may benefit from low gestational weight gain. In developing countries the paucity of research on weight gain in pregnancy and obstetric and neonatal outcomes gives cause for concern. Anaemia and low birth weight is relatively common and poor weight gain has been found to contribute to these. ${ }^{14}$ Pregnant women in these countries generally start antenatal care late and early BMI will be difficult to determine. In addition weight gain will be influenced by seasonal availability of food especially in rural areas as well as high parity and breast feeding patterns. ${ }^{27}$

A proposal from South Africa in which monitoring of pregnant women can be done with measurements of height, weight and mid-upper arm circumference (MUAC) to classify them into various risk categories is worth exploring. ${ }^{28}$

\section{CONCLUSION}

This study has shown an association between maternal overweight and obesity and adverse pregnancy outcomes including higher caesarean section rates, stillbirths, fetal macrosomia, post-partum haemorrhage and retained placenta. Normal fetal outcome is possible throughout the range of BMI and weight gain. 
It is recommended that studies enrolling larger sample sizes such as in hospitals delivering over 5,000 women per year are carried out as these are more likely to yield results comparable to those found in the large population based studies in the developed countries and add to data which is currently lacking in developing countries. There is also the need to develop guidelines on weight gains to optimize pregnancy and neonatal outcomes.

\section{REFERENCES}

1. Varma TR, Maternal weight and weight gain in pregnancy and obstetric outcome, Int J Gynaecol Obstet. 1984 Apr; 22(2):161-6.

2. Lawoyin TO, Maternal Weight and Weight Gain in Africans. Its relationship to Birth Weight, Journal of Tropical Pediatrics 1991; 37(4):166171.

3. Tulman L, Morin KH, Fawcett J, Prepregnant Weight and Weight Gain During Pregnancy: Relationship to Functional Status, Symptoms, and Energy,

4. Suitor CW. 1997. Maternal Weight Gain: A Report of an Expert Work Group. Arlington, VA: National Center for Education in Maternal and Child Health.

5. Marsoosi V, Jamal A, Eslamian L, Pre-pregnancy weight, low pregnancy weight gain, and preterm delivery, Int J Gynaecol Obstet. 2004; 87:36-37

6. Kumari AS, Pregnancy outcome in women with morbid obesity, Int $J$ Gynaecol Obstet. 73(2001).101-107

7. Ekblad U, Grenman S, Maternal weight, weight gain during pregnancy and pregnancy outcome, Int J Gynae Obstet. 1992;39(4): 277-283

8. Wells C, Murra EK, Weight Gain During Pregnancy: Colorado Pregnancy Risk Assessment Monitoring System (PRAMS), 1997-2000, Colorado department of public Health and environment

9. Abrams B, Altman SL, Pickett KE, Pregnancy weight gain: still controversial 1-4 Am J Clin Nutr 2000; 71( suppl):1233S-41S.

10. Bracero LA, Byrne DW, Optimal Maternal Weight Gain during Singleton Pregnancy Gynecologic and Obstetric Investigation 1998; 46:9-16.

11. Carmichael S, Abrams B, Selvin S, The Pattern of Maternal Weight Gain in Women with Good Pregnancy Outcomes, Am J Public Health 1997; 87:1984-1988

12. Bhattacharya S, Campbell DM, Liston WA, Bhattacharya S, Effect of Body Mass Index on pregnancy outcomes in nulliparous women delivering singleton babies BMC Public Health 2007, 7:168 doi: 10.1186/1471-2458-7-168 http://www.biomedcentral.com/1471-2458/7/168
13. Wood L. Obesity, waist-hip ratio and huntergatherers. BJOG 2006; 113:1110-1116.

14. Sahu MT, Agarwal A, Das V, Pandey A, Impact of maternal body mass index on obstetric outcome: $J$ Obstet Gynaecol Res. 2007 Oct; 33(5):655-9.

15. Doherty DA, Magan EF, Francis J, Morrison JC, Newnham JP, Pre-pregnancy body mass index and pregnancy outcomes. Int J Gynaecol Obstet. 95 (2006), 242-247

16. National collaborating centre for women's and children's health. Antenatal care routine care for the healthy pregnant woman. NICE/RCOG press 2008.

17. Cedergren $M$,Effects of gestational weight gain and body mass index on obstetric outcome in Sweden . Int J Gynaecol Obstet. (2006) 93, 269274.

18. Beilly JS. Kurland I. Relationship of maternal weight gain and weight of the newborn infant. $A m$ J Obstet Gynecol 150: 1945: 202-206.

19. Hytten FE, Leitch I. The Physiology of Human Pregnancy, (2nd ed), Blackwell Scientific Publications, Oxford, (1971), pp. 265-285.

20. Rosso P, A new chart to monitor weight gain during pregnancy. Am J Clin Nutr 41,(1985) 644652.

21. National Academy of Sciences, Institute of Medicine, Food and Nutrition Board, Nutrition During Pregnancy Part I-Weight Gain. Part IINutrient Supplements, Committee on Nutritional Status During Pregnancy and Lactation, Subcommittee on Dietary Intake and Nutrient Supplements During Pregnancy, Subcommittee on Nutritional Status and Weight Gain During Pregnancy. 1990. Washington, DC: National Academy Press

22. Biritwum RB, Gyapong J, Mensah G, The epidemiology of obesity in Ghana, Ghana Med $J$ 39 (3): 2003: 82- 85.

23. Ofei F, Obesity- a preventable disease, Ghana Med J 39 (3): 2003: 98- 101.

24. Cnattingius S, Bergstrom R, Lipworth L, Kramer MS. Prepregnancy weight and the risk of adverse pregnancy outcomes. N Engl J Med; 338: 1998: 147- 52 .

25. Sebire NJ, Jolly M, Harris JP, et al. Maternal obesity and pregnancy outcome: a study of 287,213 pregnancies in London. Int J Obes Relat Metab Disord; 25: 2001: 1175-82.

26. Edwards LE, Hellerstedt WL, Alton IR, et al. Pregnancy complications and birth outcomes in obese and normal-weight women: effects of gestational weight change. Obstet Gynecol; 87:1996: 389- 94 .

27. Hartikainen H, Maleta, KH, Kulmala T, Ashorn, P, Seasonality of gestational weight gain and foetal 
growth in rural Malawi, East African Medical Journal Vol.82(6) 2005: 294-299

28. Kruger HS Maternal anthropometry and pregnancy outcomes: a proposal for the monitoring of pregnancy weight gain in outpatient clinics in South Africa. Acta Obstet Gynecol Scand. 2007; 86(1):26-32 